\title{
SEROPREVALENCIA DEL VIRUS DE LARINOTRAQUEITIS INFECCIOSA BOVINA EN GANADO LECHERO DEL VALLE DE LIMA
}

\author{
Gabriela Sánchez T. ${ }^{1}$, Alfredo Benito Z. ${ }^{2}$ y Hermelinda Rivera G. ${ }^{2,3}$
}

\section{AbSTRACT}

The seroprevalence of bovine herpes virus type 1 (BHV-1), the causative agent of Infectious Bovine Rhinotracheitis (IBR) was determined in non-vaccinated bovines older than 6 months of age and reared in 12 dairy farms in the valley of Lima, Peru. Blood samples were collected from 395 animals and assayed for antibodies to BHV-1 by using virus neutralization test. Antibodies against BHV-1 were detected in $26 \pm 0.47 \%(143 / 395)$ of the animals with titers between 2 and $>256$. Sixty seven per cent $(8 / 12)$ of herds had seropositive animals. The higher prevalence was found in herds with more than 300 animals and in herds located in the north and south of Lima, and in those animals older than 2 years. These results confirmed the wide distribution of BHV-1 in the Lima valley, despite of the absence of clinical signs. Since farmers have indicated to have observed respiratory diseases in young animals, the BHV-1 would be associated to the bovine respiratory complex in calves.

Key words: bovine, bovine herpes virus type 1, BHV-1, infectious bovine rhinotracheitis, antibodies, dairy herds

\section{RESUMIEN}

El presente estudio tuvo como objetivo determinar la seroprevalencia del virus herpes bovino tipo 1 (VHB-1), agente causal de la Rinotraqueitis Infecciosa Bovina (RIB), en bovinos mayores de 6 meses de edad, procedentes de 12 hatos lecheros del valle de Lima y sin historia de vacunación. Se tomó muestras de sangre en 395 hembras para la detección de anticuerpos neutralizantes en suero mediante la prueba de neutralización viral. El $36 \pm 0.47 \%$ (143/395) de los animales presentaron anticuerpos neutralizantes contra el VHB-1 con títulos entre 2 a >256. El 67\% (8/12) de los hatos muestreados tuvieron animales seroreactores. Las mayores prevalencias se presentaron en hatos con $>300$ animales, en hatos ubicados en el norte y sur del valle de Lima y en animales mayores de 2 años de edad. Estos resultados confirman que el VHB-1 está difundido en el valle de Lima a pesar que no se obtuvo evidencias clínicas de la RIB. Sin embargo, considerando que los ganaderos manifestaron observar problemas respiratorios en animales jóvenes, esto podría ser indicativo que el virus estaría asociado al complejo respiratorio bovino.

Palabras clave: bovinos, virus herpes bovino tipo 1, VHB-1, Rinotraqueitis Infecciosa Bovina, anticuerpos neutralizantes, hatos lecheros

\footnotetext{
${ }^{1}$ Práctica privada

${ }^{2}$ Laboratorio de Microbiología y Parasitología, FMV-UNMSM

${ }^{3}$ E-mail: hriverag@vet.unmsm.edu.pe
} 


\section{INTRODUCCIÓN}

La mayoría de los establos lecheros del valle de Lima tiene una población de 100 a 400 animales y pocos tienen más de 500 (INEI, 1995). Se tiene un sistema de crianza intensiva con niveles de tecnología medio a alto y con adecuados índices productivos que los hacen vulnerables a factores tales como el estrés, clima y enfermedades infecciosas.

Estudios realizados en bovinos del valle de Lima indican que algunas infecciones virales, bacterianas o por protozoos son prevalentes (Aguilar, datos no publicados; Silva et al, 2002). Muchas de estas enfermedades fueron introducidas con la importación de animales, y la cuenca de Lima ha sido la de mayor riesgo ya que los animales importados cumplen el periodo cuarentenario en el puerto del Callao.

Se describe que durante una de estas cuarentenas en 1965 , se presentaron casos clínicos de Rinotraqueitis Infecciosa Bovina (RIB) en un grupo de vaquillonas procedentes de USA (De la Vega, comunicación personal). A partir de esa fecha, y por evaluaciones serológicas se ha determinado que la infección está distribuida en forma subclínica en varias zonas del país, aunque no se ha hecho reporte de presencia clínica.

La RIB es una enfermedad de distribución mundial y producida por el virus herpes bovino tipo 1 (VHB-1), de la familia Herpesviridae, subfamilia Alphaherpesvirinae y género Varicellovirus (Pidone et al., 1999). Este virus se transmite de forma directa de un animal a otro por medio de las secreciones corporales o de forma indirecta por el personal o equipos contaminados. Las puertas de ingreso serían la cavidad nasal, orofaringe, tracto genital y ojos. Los síntomas observados como la rinotraqueitis, conjuntivitis, vulvovaginitis y balanopostitis se deben a la destrucción de las células epiteliales como resultado de la replicación viral que ocurre en el lugar de ingreso (Engels y Ackermann, 1996; Pidone et al., 1999).
Usualmente estas lesiones suelen complicarse con infecciones bacterianas secundarias, debido al efecto inmunodepresor del virus sobre el mecanismo de defensa antibacterial de los pulmones. La complicación más común y severa es el complejo respiratorio bovino donde están involucrados otros virus como el virus de la diarrea viral bovina, el virus respiratorio sincitial, los adenovirus, reovirus y coronavirus y el Parainfluencia-3; y bacterias como Pasteurella haemolitica, Pasteurella multocida, chlamydia y micoplasma.

$\mathrm{Al}$ inicio, los agentes virales realizan un daño epitelial causado por la severa inflamación pulmonar, lo que favorece el crecimiento de bacterias como la Pasteurella, causando problemas de neumonías y bronconeumonías; que podrían ser de curso fatal, sobre todo en animales jóvenes o susceptibles, como se reportó en terneros de hatos lecheros y toros de engorde del valle de Lima (Rivera et al., 1994; Pidone et al., 1999; Zanabria et al., 2000). La RIB puede causar abortos, posiblemente, como secuela del problema respiratorio, debido al aumento de la temperatura corporal (Rivera et al., 1993).

El VHB-1 puede persistir en forma latente en las neuronas ganglionares del trigémino o sacro, e incluso en las tonsilas. Bajo condiciones de estrés el virus puede ser reactivado y causar infecciones usualmente de tipo subclínica; siendo una fuente de infección para animales susceptibles (Favoreel et al., 2000; Winkler et al., 2000).

A pesar de las pérdidas económicas que ocasiona este agente viral, no existe datos concretos de su prevalencia en bovinos del valle de Lima y por lo tanto, se dificulta la formulación de medidas de prevención y control. Es por ello, que el presente estudio tuvo por objetivo determinar la seroprevalencia del VHB-1 en bovinos mayores de 6 meses de edad de hatos lecheros sin historia de vacunación contra dicho agente. 


\section{MatidRiales y Mútiodos}

\section{Localización y animales}

El estudio se realizó en doce establos lecheros de crianza intensiva del valle de Lima, durante los meses de enero y febrero del 2002, y que por motivos de análisis se agruparon según su ubicación como hatos de la zona norte, centro y sur.

Se utilizó bovinos hembras mayores de 6 meses de edad, procedentes de establos lecheros sin historia de vacunación contra VHB-1 o que hayan transcurrido al menos 5 años desde la última vacunación. Para efectos del análisis, los animales se distribuyeron en dos grupos etarios: menores de dos años (vaquillas) y mayores de dos años (vacas en producción).

\section{Reactivos y cultivos celulares}

Se utilizó cultivos secundarios de células de cornete nasal de feto bovino, libres de VDVB como sistema indicador de la prueba de neutralización viral. Las células fueron cultivadas empleando medios de cultivo MEN (Minimum Essencial Medium) y L-15 (Leibowitz) (Sigma, USA), en una proporción 50:50 suplementadas con el 10\% de suero fetal bovino libre de VDVB (Sigma, USA) y antibióticos.

Se utilizó la cepa Cooper (Ames, USA) como antígeno, cepa prototipo del VHB-1 con un título de $10^{-5} \mathrm{DI}_{50} \mathrm{CC} / 50 \quad 1$.

\section{Tamaño muestral}

El tamaño de la muestra $(n=296)$ fue determinado mediante el método de muestreo simple al azar, empleando una prevalencia del 26\% (Rivera et al., 1993), con un nivel de confianza de $95 \%$ y un error de $5 \%$ (Thursfield, 1990).

La población muestreal se estratificó de acuerdo a la población de cada establo.

\section{Obtención y análisis de muestras}

Se recolectó muestras de sangre por punción venosa en tubos vacutainers, y fueron procesadas en el Laboratorio de Virología de la Facultad de Medicina Veterinaria de la Universidad Nacional Mayor de San Marcos. Los sueros se obtuvieron por centrifugación a 3,000 rpm por 5 minutos, y se almacenaron en congelación $-20^{\circ} \mathrm{C}$ hasta su utilización en la prueba de neutralización viral, según la técnica descrita por la Office International des Epizooties (2000).

El título del suero fue la dilución más alta capaz de neutralizar el 75 a $100 \%$ de la capacidad infectante del virus, evidenciado por la ausencia de lesión celular. Los títulos del suero iguales o mayores a 1:2 fueron considerados positivos a anticuerpos.

\section{Análisis de datos}

Se determinó la seroprevalencia del BHV-1 y los intervalos de confianza (IC) del $95 \%$.

El efecto de las variables de zona de muestreo, edad, y tamaño poblacional sobre la presencia de anticuerpos contra el VHB-1 fue evaluado mediante la prueba de regresión logística, que determina y cuantifica la presencia de asociación entre las variables en estudio.

\section{Resultados}

El $36 \pm 0.047 \%(143 / 395)$ de las muestras estudiadas tuvieron anticuerpos neutralizantes contra el VHB-1. La prevalencia viral dentro del hato estuvo entre 2 a $90 \%$. Se detectaron anticuerpos contra el VHB-1 en las tres zonas de muestreo, con una prevalencia que varió entre 13 a $50 \%$. La prevalencia viral fue mayor en los establos con mayor tamaño poblacional, así como en animales de más de dos años (Cuadro 1). La distribución de los títulos de anticuerpos contra el VHB-1 se encuentra entre el rango de 2 a $>256$ (Cuadro 2). 
Cuadro 1. Seroprevalencia del virus herpes bovino tipo 1 en bovinos lecheros del valle de Lima, mediante la prueba de neutralización viral. 2002

\begin{tabular}{|c|c|c|c|c|}
\hline \multirow[b]{2}{*}{ Variable } & \multirow{2}{*}{ Grupo } & \multirow{2}{*}{$\begin{array}{c}\mathrm{N}^{\mathrm{o}} \mathrm{de} \\
\text { muestras }\end{array}$} & \multicolumn{2}{|c|}{ Positividad } \\
\hline & & & $\mathrm{N}^{\mathrm{o}}$ & $\%$ \\
\hline \multirow{12}{*}{ Establos } & 1 & 12 & - & - \\
\hline & 2 & 46 & 1 & $2 \pm 0.04$ \\
\hline & 3 & 70 & 63 & $90 \pm 0.07$ \\
\hline & 4 & 29 & 3 & $10 \pm 0.11$ \\
\hline & 5 & 20 & 14 & $70 \pm 0.20$ \\
\hline & 6 & 40 & 7 & $18 \pm 0.12$ \\
\hline & 7 & 15 & - & - \\
\hline & 8 & 24 & - & - \\
\hline & 9 & 25 & - & - \\
\hline & 10 & 22 & 9 & $41 \pm 0.21$ \\
\hline & 11 & 42 & 16 & $38 \pm 0.15$ \\
\hline & 12 & 50 & 30 & $60 \pm 0.14$ \\
\hline \multirow{3}{*}{ Zona de muestreo } & Norte & 177 & 81 & 46 \\
\hline & Centro & 126 & 16 & 13 \\
\hline & Sur & 92 & 46 & 50 \\
\hline & $<2$ años & 52 & 6 & 12 \\
\hline Edad & $>2$ años & 343 & 137 & 40 \\
\hline \multirow{2}{*}{ Tamaño poblacional $^{1}$} & Mediano & 123 & 26 & 21 \\
\hline & Grande & 272 & 117 & 43 \\
\hline Total & 12 & 395 & 143 & $36 \pm 0.047 \%$ \\
\hline
\end{tabular}

${ }^{1}$ Mediano: 50-300 animales; Grande: 301-500 animales

El análisis de regresión logística muestra que las variables zona de muestreo norte y sur, así como edad $>2$ años representan factores de riesgo asociados a la infección. En esta evaluación se considera a la zona centro y a la edad $<2$ años como estratos de referencia debido a que ellos presentan el menor porcentaje de animales infectados. No hubo asociación de riesgo por tamaño poblacional (Cuadro 3).

Cuadro 2. Distribución de los títulos de anticuerpos contra VHB-1 presentes en el suero, según la edad de bovinos de establos lecheros del valle de Lima. 2002

\begin{tabular}{crccc}
\hline \multirow{2}{*}{ Edad } & \multicolumn{5}{c}{ Inversa de la dilución de los títulos de anticuerpos } \\
\cline { 2 - 5 } & $<2$ & $2-8$ & $16-64$ & $128->256$ \\
\hline$<2$ años & 46 & 1 & 4 & 1 \\
$>2$ años & 206 & 49 & 77 & 11 \\
\hline Total & 252 & 50 & 81 & 12 \\
\hline
\end{tabular}


Cuadro 3. Resultados de Odds Ratio a partir de la evaluación del efecto de las variables zona de muestreo, edad y tamaño poblacional sobre la presencia de anticuerpos contra VHB-1, mediante la prueba de regresión logística, en muestras de bovinos lecheros del valle de Lima. 2002

\begin{tabular}{|c|c|c|c|c|}
\hline \multirow{2}{*}{ Variable } & \multirow{2}{*}{$\begin{array}{l}\text { Nivel de } \\
\text { significancia }\end{array}$} & \multirow{2}{*}{ Odds Ratio } & \multicolumn{2}{|c|}{ IC del $95 \%$ del OR } \\
\hline & & & Límite inferior & Límite superior \\
\hline Zona norte & 0.000 & 5.43 & 2.93 & 10.06 \\
\hline Zona sur & 0.000 & 6.11 & 2.95 & 12.62 \\
\hline Edad (>2 años) & 0.001 & 4.95 & 1.96 & 12.47 \\
\hline $\begin{array}{l}\text { Tamaño poblacional } \\
\text { (> } 300 \text { animales) }\end{array}$ & 0.109 & 1.60 & 0.90 & 2.86 \\
\hline
\end{tabular}

\section{Discusión}

La presencia de anticuerpos contra el VHB-1 indica que esos animales tuvieron experiencia con el agente viral. El 36\% de prevalencia detectado corrobora los hallazgos serológicos en bovinos lecheros de otras cuencas como Cajamarca y Arequipa, donde la prevalencia del VHB-1 no supera el $40 \%$; a diferencia de otras infecciones como leucosis o diarrea viral bovina (DVB), cuyas prevalencias superan el $50 \%$ en esta misma población de animales (Rivera H., comunicación personal).

Esta relativa baja prevalencia del VHB1 comparado con otros agentes virales como la DVB en hatos lecheros de crianza intensiva sugiere la existencia de factores que minimizan la diseminación viral entre los establos del valle de Lima. Uno de estos factores podría ser el clima que no contribuye a la presentación clínica de la enfermedad como sucede en países con severos inviernos donde la prevalencia viral puede alcanzar hasta $80 \%$ (Banks, 1999).

Un animal con infección aguda o subclínica elimina el virus en las secreciones oculares y nasales; y aun cuando el virus es muy lábil en el medio ambiente habría una mayor oportunidad para ser transmitido a otro animal susceptible del mismo establo, lo que explicaría la prevalencia viral hasta de $90 \%$ en algunos hatos muestreados (Cuadro 1). En contraste con el ganado lechero, el VHB1 presenta hasta un $75 \%$ de incidencia en toros de centros de engorde (Zanabria et al., 2000), donde al parecer el severo estrés de transporte, la presencia de otros agentes infecciosos, deficiencias en el manejo, etc., favorecen la reactivación y replicación o infección primaria con el virus por ser animales inmunodeprimidos (Banks, 1999).

Estudios recientes en el país han demostrado que el VHB-1 tiene mayor prevalencia (68\%) en bovinos criollos de crianza extensiva de Ayacucho (Zacarías et al., 2002), donde los animales están sujetos a factores estresantes como la sequía, falta de pastos, desnutrición y parasitosis principalmente; estos factores podrían favorecer la reactivación viral con presentación aguda o subclínica de la RIB con eliminación viral y transmisión a los animales susceptibles, incluyendo a otros rumiantes domésticos en crianzas de tipo mixto.

Los ganaderos no reportaron la ocurrencia clínica del RIB en animales adultos, pero se observó que habían problemas respi- 
ratorios en los animales jóvenes. La ocurrencia del complejo respiratorio en terneros de un establo lechero, donde el VHB-1 fue uno de los principales agentes infecciosos ha sido documentado (Rivera et al., 1994).

El 36\% de animales reactores mayores a 6 meses serían animales infectados, en donde el virus permanece en estado de latencia, ya que éste se encuentra en los ganglios trigémino, sacro y tonsilas del animal infectado (Engels y Ackermenn, 1996; Mettenleiter, 2000). Es posible que el virus se reactive en algunos animales ocasionando infecciones recurrentes de tipo subclínico y transmisiones horizontales si existen animales susceptibles (Van Oirschot, 1995; Banks, 1999).

Si se toma en cuenta que la forma subclínica es la que predomina en el valle de Lima, uno de los eventos que podría contribuir a la transmisión horizontal del virus a animales adultos son las exposiciones ganaderas. Estos animales adultos son vacas de alta producción lechera y buena eficiencia reproductiva y, por lo tanto, bajo estrés constante, teniendo como resultado animales susceptibles (Schettino et al., 1996).

Los títulos de anticuerpos neutralizantes detectados variaron de 2 a $>256$, pero mayormente de 2 a 64 (131/143). Estos títulos expresan la respuesta del animal como consecuencia de una infección primaria, reactivación o reinfección viral (Cuadro 2). El caso de la vaquilla que desarrolló un alto título neutralizante (128 a >256), se pudo deber a una infección reciente.

Los resultados del estudio evidencian una activa transmisión del VHB-1 en hatos lecheros del valle de Lima. Si bien es cierto, que los ganaderos manifestaron desconocer la evidencia de signos clínicos de la RIB, la infección del VHB-1 puede ocasionar problemas respiratorios evidenciados por los estudios de Rivera et al. (1994) y Zanabria et al. (2000); y quizás problemas reproductivos como lo relaciona de forma indirecta Rivera et al. (1993).

\section{Litidratura Citada}

1. Banks, M. 1999. Living with IBR. Holstein J. 3: 84-87.

2. Engels, M.; M. Ackermenn. 1996. Pathogenesis of rumiant herpesvirus infections. Vet. Microbiol. 53: 3-15.

3. Favoreel, H.; H. Nauwgnck; M. Pensaert. 2000. Immunological hiding of herpesvirus-infected cells. Arch. Virol. 145: 1269-1290.

4. INEI. Instituto Nacional de Estadística e Informática. 1995. III Censo Nacional Agropecuario. Lima, Perú.

5. Mettenleiter, T. 2000. Aujeszky's (pseudorabies) virus: the virus and molecular pathogenesis. State of the art. Vet. Res. 31: 99-115.

6. Office International des Epizooties. 2000. Infectious bovine rhinotracheitis/ infectious pustular vulvo-vaginitis. En: Manual of standards diagnostic tests and vaccines. p 322-328.

7. Pidone, H.; C. Galosi; M. Etcheverrigaray. 1999. Herpes bovinos 1 y 5 . Analecta Argentina 19: 40-50.

8. Rivera, H.; A. Manchego; N. Sandoval. 1993. Aborto infeccioso en bovinos de leche del valle de Lima. Rev. Inv. Pec. IVITA 6: 31-37.

9. Rivera, H.; A. Manchego; N. Sandoval. 1994. Complejo respiratorio bovino en terneros del valle de Lima. Rev. Inv. Pec. IVITA 7: 35-38.

10. Schettino, D.; M. Santo; L. Gogorza; G. Arroyo; J. Torres; P. Morán. 1996. Comportamiento epidemiológico de la Rinotraqueitis Infecciosa Bovina en un rodeo de cría y otro de tambo. Tandil, Buenos Aires, Argentina. Avances Cienc. Vet. 11:30-36.

11. Silva, P.; A. Chávez; H. Rivera; E. Casas. 2002. Seroprevalencia de Neospora caninun en bovinos lecheros del valle de Lima. Rev. Inv. Vet. Perú 13: 51-55.

12. Thursfield, M. 1990. Epidemiología veterinaria. p 42. Ed. Acribia. España. 
13. Van Oirschot, J. 1995. Bovine herpesvirus 1 in semen of bulls and the risk of transmission: A brief review. Vet. Quart. 17: 29-33.

14. Winkler, M.; A. Doster; C. Jones. 2000. Persistence and reactivation of bovine herpesvirus 1 in the tonsils of latently infected calves. J. Virol. 74: 5337-5346.

15. Zacarías, E.; A. Benito; H. Rivera. 2002. Seroprevalencia del virus de la
Rinotraqueitis Infecciosa Bovina en bovinos criollos de crianza extensiva de la provincia de Parinacochas, Ayacucho. Rev. Inv. Vet. Perú 13: 61-65.

16.Zanabria, V.; H. Rivera; R. Rosadio. 2000. Etiología del síndrome neumónico agudo en vacunos de engorde en Lima. Rev. Inv. Vet. Perú. 11: 67-85. 